Cytogenetic and Genome Research

\title{
Open Chromatin in Plant Genomes
}

\author{
Wenli Zhang Tao Zhang Yufeng Wu Jiming Jiang \\ Department of Horticulture, University of Wisconsin-Madison, Madison, Wis., USA
}

\section{Key Words}

Chromatin accessibility · cis-regulatory element · DNase I sensitivity Open chromatin

\section{Abstract}

Sensitivity to DNase I digestion is an indicator of the accessibility and configuration of chromatin in eukaryotic genomes. Open chromatin exhibits high sensitivity to DNase I cleavage. DNase I hypersensitive sites (DHSs) in eukaryotic genomes can be identified through DNase I treatment followed by sequencing (DNase-seq). DHSs are most frequently associated with various cis-regulatory DNA elements, including promoters, enhancers, and silencers in both animal and plant genomes. Genome-wide identification of DHSs provides an efficient method to interpret previously un-annotated regulatory DNA sequences. In this review, we provide an overview of the historical perspective of DHS research in eukaryotes. We summarize the main achievements of DHS research in model animal species and review the recent progress of DHS research in plants. We finally discuss possible future directions of using DHS as a tool in plant genomics research.

(c) 2014 S. Karger AG, Basel
The packaging status of chromatin is directly associated with local or global accessibility of underlying DNA to trans-acting factors which ultimately affects gene expression. Open chromatin is referred to chromatin with open conformation, facilitating changes at the underlying accessible cis-regulatory elements [Bell et al., 2011], and is generally associated with regulatory regions that are nucleosome-free or depleted. Open chromatin exhibits high sensitivity to any DNA shearing processes, including (a) physical shearing, such as sonication, (b) biochemical shearing through enzymes, including endonuclease deoxyribonuclease I (DNase I) which cuts single- and double-stranded DNA and chromatin and releases products with $5^{\prime}$-phosphorylated and 3 '-hydroxylated ends without any sequence preference, endonuclease deoxyribonuclease II (DNase II) which hydrolyzes DNA under acidic conditions and yields products with $3^{\prime}$-phosphates, micrococcal nuclease (MNase) which preferentially cleaves linker DNA between 2 nucleosomes, and other restriction enzymes [Todd and Harrison, 1979; Wu, 1980; Keene et al., 1981; McGhee et al., 1981; Kaye et al., 1984; Scott et al., 1984], and (c) chemical cleavage using reagents such as methidiumpropyl-EDTA, iron (II) (MPEiFe (II))

\section{KARGER}

E-Mail karger@karger.com www.karger.com/cgr (c) 2014 S. Karger AG, Base

1424-8581/14/1433-0018\$39.50/0
Jiming Jiang

Department of Horticulture

University of Wisconsin-Madison

Madison, WI 53706 (USA)

E-Mail jjiang1@ wisc.edu 


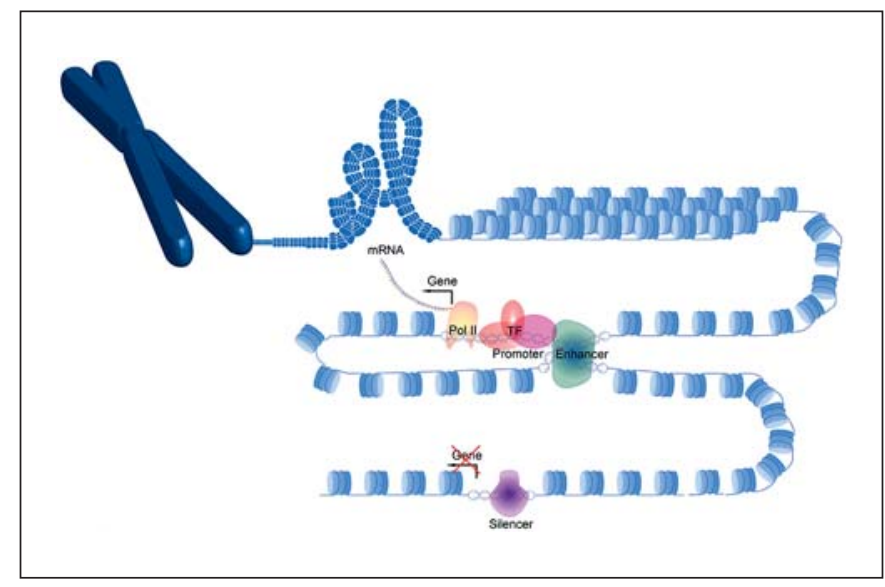

Fig. 1. Gene expression regulated by binding of regulatory proteins to cis-regulatory DNA elements. Bindings of transcription factors to promoters and enhancers lead to gene expression, whereas binding of a repressor protein to silencers leads to gene silencing. cies-specific manners. DHS mapping is a powerful and straightforward way to identify all regulatory elements across the genome, including promoters, enhancers, silencers, insulators, and locus control regions [John et al., 2013]. High throughput mapping of DHSs across a genome has enabled a better understanding of how chromatin structure is regulated in cell/tissue differentiation and species specification in model animal species [Birney et al., 2007; Thurman et al., 2012; Vernot et al., 2012; Winter et al., 2013]. Research on chromatin accessibility represented by DHSs in plants, however, has lagged behind model animal species. Here, we review the progress of DHS identification in plant genomes. Our focus includes historical perspectives of DHS research in model animal genomes, adaptation of DHS identification methodology in plants, and updates of recent DHS research in plant genomes.

\section{Methodologies for DHS Identification}

\section{Classical Methodologies for Identification of DHSs}

The traditional method to identify a DHS includes the partial fragmentation of intact nuclear chromatin by using DNA cleavage enzymes or chemical cleavage reagents coupled with Southern blot hybridization or polymerase chain reaction (PCR). For example, DHSs located within either the $5^{\prime}$ - and/or $3^{\prime}$-regions of active genes can be individually detected using conventional Southern blotbased assays [Elgin, 1981; Eissenberg et al., 1985; Gross and Garrard, 1988; Krebs and Peterson, 2000]. This technique was used to map DHSs associated with heat shock genes in Drosophila [Wu, 1980; Keene et al., 1981], globin genes in chicken and humans [Stalder et al., 1980; Groudine et al., 1983], and the metallothionein gene and several other genes in mouse [Mather and Perry, 1983; Senear and Palmiter, 1983; Bender et al., 2000; Bulger et al., 2003]. Similarly, DHSs across approximately $300 \mathrm{~kb}$ of the human genome were profiled using quantitative PCR assays (qPCR). These DHSs were also found to be associated with classical cis-regulatory functions, such as promoters, enhancers, locus control regions, insulators, and other novel elements [Pfeifer and Riggs, 1991; Feng and Villeponteau, 1992; McArthur et al., 2001; Dorschner et al., 2004; Martins et al., 2007]. DHSs distributed within the TAL1/SCL locus (T-cell acute lymphocytic leukaemia-1), also known as SCL (stem cell leukemia) between human embryonic stem cells and K562 cells, were successfully mapped using real-time PCR analysis [Follows et al., 2007]. 
High-Throughput Methodologies for Identification of DHSs

The Southern blot-based DHS assay is time-consuming and low throughput. This method is only suitable for analysis of a single locus or short stretch of DNA sequences. With the advent of high throughput sequencing techniques, several methods have been developed to identify and map DHSs across an entire genome. Among these methods, DNase I digestion followed by sequencing (DNase-seq) [Boyle et al., 2008] has been applied for identification of DHSs in several species. This method includes isolation of nuclei, DNase I digestion, end-blunting of DNase I digested high molecular weight DNA, sequential ligation with 2 different adaptors, and Illumina sequencing after PCR enrichment of ligated DNA fragments. DHS maps have been developed in several model animal species with sequenced genomes, such as human, mouse, and Drosophila [Crawford et al., 2004, 2006a, b; Sabo et al., 2004, 2006; Weil et al., 2004; Boyle et al., 2008; Song and Crawford, 2010]. In addition to DHS mapping, formaldehyde-assisted isolation of regulatory elements (FAIRE) [Giresi et al., 2007], chromatin immunoprecipitation (ChIP) [Johnson et al., 2007], MNase-seq [Schones et al., 2008], Sono-seq [Auerbach et al., 2009], NOMe-seq [You et al., 2011], MeDIP footprint assay [Bell et al., 2010], and ATAC-seq [Buenrostro et al., 2013] have also provided supplemental information to indicate the presence of open chromatin. For example, FAIRE is a method to isolate and identify nucleosome-depleted regions in the genome which was initially established in yeast and has also been applied to human [Giresi et al., 2007; Hogan et al., 2006] and maize [Louwers et al., 2009]. Similar to DNase-seq, FAIRE appears to efficiently map all CREs. DNase-seq and FAIRE have been used as complementary methods for identifying open chromatins in human [Song et al., 2011].

DNase-seq, FAIRE-seq, and ChIP-seq are the most commonly used methodologies for identification of open chromatin. Each method has its own advantages and disadvantages. DNase-seq is the gold standard in identifying all CREs, but it can't distinguish between active and posed DNA elements. FAIRE-seq cannot distinguish permanent interaction from transient interaction between DNA and trans-acting factors after formaldehyde fixation. ChIP-seq requires a specific antibody recognizing a specific trans-acting factor bound to various genomic loci. Similarly, Sono-seq needs chromatin cross-linking and sonication for chromatin fragmentation which has limitations similar to FAIRE-seq. NOMe-seq offers the ability to profile both nucleosome occupancy and CpG meth- ylation on the same DNA strand, but it depends on a methyltransferase which in vitro marks open chromatin containing GC methylation. Thus, any factor affecting the accessibility of the enzyme to the DNA will mask open chromatin identification.

Several other methods have been developed for identifying higher-order chromatin structure and dynamics, including 3C (chromosome conformation capture) [Dekker et al., 2002], 4C (circular chromosome conformation capture and chromosome-conformation-capture-on-chip) [Zhao et al., 2006], 5C (chromosome conformation capture carbon copy) [Dostie and Dekker, 2007], 6C (combined chromosome conformation capture ChIP cloning) [Tiwari et al., 2008], Hi-C [Lieberman-Aiden et al., 2009], and ChIA-PET (chromatin interaction analysis by pairedend tag sequencing) [Fullwood et al., 2009]. These methods can be applied to study long-range chromatin interactions that occurred locally or globally within the genome and can be potentially used for studying chromatin accessibility [Sajan and Hawkins, 2012].

\section{Genomic Locations of DHSs}

A relative high DHS-positive rate associated with some silenced genes was observed in HeLa S3 cells which either suggests that chromatin related to inactive genes still retains a certain degree of openness and accessibility [Wang et al., 2012] or indicates that those DHS-associated silenced genes are poised for expression through RNA polymerase II binding in a development dependent manner [Muse et al., 2007; Zeitlinger et al., 2007]. DHSs, however, are generally not associated with inactive genes. The presence of DHSs is thus viewed as a method for identification of active genes or genes poised for tissue-specific expression [Krebs and Peterson, 2000]. The main types of DHSs within cell types or tissues fall into the following 4 categories: constitutive, inducible, tissue specific, and development specific [Gross and Garrard, 1988]. Constitutive and inducible DHSs are usually found in gene promoter regions. The vast majority of well described DHSs are associated with functional genomic elements [Eissenberg et al., 1985; Gross and Garrard, 1988; Krebs and Peterson, 2000; Cockerill, 2011], including enhancers [McGinnis et al., 1983; Nelson and Groudine, 1986], silencers [Fritton et al., 1983; Shore et al., 1987], promoters [Wu et al., 1979; Stalder et al., 1980; Wu, 1980; Ferl and Nick, 1987], terminators [Almer et al., 1986; Gargiulo et al., 1985; Yagi et al., 1986], upstream activation sequences [Lohr, 1984], replication origins [Varshavsky et al., 1979; Borchsenius et al., 1981; Fagrelius and Livingston, 1984], locus control regions [Grosveld et al., 1987], topoisomer- 
ase sites [Ness et al., 1986; Udvardy et al., 1986; Thomsen et al., 1987], recombination loci [Storb et al., 1981; Fagrelius and Livingston, 1984], centromeres [Bloom and Carbon, 1982], and telomeres [Budarf and Blackburn, 1986]. These elements are known to function in a series of essential biological processes such as gene transcription, DNA replication, recombination, and DNA repair.

\section{DHSs in the Human Genome}

DHS mapping has been used as a powerful tool to identify CREs in the human genome. It is one of the most important methodologies used in the ENCODE (Encyclopedia of DNA Elements) project in human [Birney et al., 2007; Bernstein et al., 2012] and other model animals [Gerstein et al., 2010; Roy et al., 2010; Stamatoyannopoulos et al., 2012] which has been proved to lead toward a comprehensive and functional annotation of genomic sequences, especially for previously incompletely annotated ones [Neph et al., 2012; Thurman et al., 2012; Vernot et al., 2012].

Most human DHSs are localized within intergenic regions, 5'-UTRs, 3'-UTRs, introns, and exons of active genes. These genomic regions are known to be associated with various CREs [Boyle et al., 2008]. Thus, CREs can be identified by the presence of DHSs together with other chromatin signatures. For example, enhancers can be identified by DHSs together with P300/CBP binding and histone modifications marks $\mathrm{H} 3 \mathrm{~K} 4 \mathrm{me} 1$ and $\mathrm{H} 3 \mathrm{~K} 27 \mathrm{ac}$ [Heintzman et al., 2007, 2009; Ong and Corces, 2011; Zentner et al., 2011; Kolovos et al., 2012]. CTCF (CCCTCbinding factor) is the only insulator protein identified in vertebrates thus far [Valenzuela and Kamakaka, 2006; Wallace and Felsenfeld, 2007]. Correlation analysis between DNase-seq and CTCF-based ChIP-seq datasets provided strong evidence that DHSs overlapping with CTCF binding sites can potentially function as insulators across the human genome, although this is not universally true as not all insulators/silencers are bound by CTCF [Wang et al., 2012].

Functionally, DHSs have been found to be closely associated with various types of biological functions, including gene expression and regulation, nucleosome stability, replication, and cohesion [Parelho et al., 2008; Shu et al., 2011; Song et al., 2011; Wang et al., 2012; Winter et al., 2013]. Most importantly, DHSs were found to be associated with phenotypic variations in humans, including human diseases [Schaub et al., 2012], such as lung disease [Bischof et al., 2012] and Type 2 diabetes [Stitzel et al., 2010].

Open Chromatin in Plants

\section{Identification of DHSs in Plants}

The local presence of DHSs within a few plant genes was identified using DNase I cleavage coupled with Southern blot hybridization, including the Adh gene in maize and Arabidopsis [Wu et al., 1979; Vega-Palas and Ferl, 1995], ribosomal RNA genes (rRNA) in barley [Dimitrova et al., 2009] and wheat [Thompson and Flavell, 1988], rbcS in pea [Gorz et al., 1988], heat-shock and abscisic acid inducible genes in wheat [Loer and Spiker, 1992], Proteinase inhibitor I in tomato [Conconi and Ryan, 1993], and HSP $70 A$ and RBCS2 in Chlamydomonas [Lodha and Schroda, 2005]. Remarkably, this Southern blot-based method was used to identify all DHSs within an 80-kb genomic region in Arabidopsis [Kodama et al., 2007a, b]. Local DHSs were also detected by DNase I digestion followed by locus-specific PCR [Shu et al., 2013]. High-throughput techniques have recently been developed in plants for genome-wide mapping of DHSs. These methods coupled partial DNase I cleavage with either next generation sequencing (DNaseseq) [Zhang et al., 2012a, b] or DNA microarray analysis (DNase-chip) [Shu et al., 2012, 2013].

The fact that cell walls and chloroplasts are present in plant cells requires an adaptation of the DNase-seq method developed for cultured cells in humans for successful application in plants. First, caution is required during nuclei isolation and purification to avoid degradation of plant nuclei/chromatin. Since sequencing reads generated from the DNase I cut sites are used to identify DHSs in DNase-seq, broken sites resulting from degradation will lead to false positive mapping results. To minimize unspecific damage to nuclei or chromatin, sucrose needs to be added to the nuclei isolation and washing buffer to stabilize the nuclei; centrifugation should be carried out at the lowest speed possible, a reduced concentration of Triton X-100 should be used in washing buffer, and washes should be kept to a minimum. Secondly, we need to thoroughly disrupt cell walls and other fibrous structures by grounding frozen plant tissues into a fine powder using liquid nitrogen. Fine grinding will also ensure the maximum yield of nuclei from a certain amount of tissue which sometimes can be a limiting factor for experiments. Lastly, we need to remove as much chloroplast contamination as possible by adding $0.4-0.5 \%$ Triton X-100 to the washing buffer and performing 2 or 3 washes until a white/yellow pellet is clearly visible. Most importantly, certain concentrations of Triton X-100 can destabilize the membrane of chloroplasts [Saxena et al., 1985]. A high concentration of Triton X-100, however, not only degrades the membrane of chloroplasts to eliminate chloro- 
plast contamination but also damages outer nuclear membranes and makes nuclei more fragile which consequently results in unspecific degradation of nuclei/chromatin [Sikorskaite et al., 2013]. Thus, concentration of Triton X-100 should be optimized depending on which tissue and species are being used for nuclei isolation.

\section{DHSs across Model Plant Genomes}

\section{Comparison of DHS Distribution in Plants and Humans}

DHSs have been identified across the entire genomes in both rice and Arabidopsis using DNase-seq [Zhang et al., 2012a, b]. Association analyses between DNase-seq and RNA-seq datasets revealed that the sensitivity of DHSs is positively correlated with the expression level of genes associated with the DHSs. DHSs were found to be more frequently associated with highly expressed genes than weakly expressed or silent genes and were associated with various types of functional DNA elements, such as the conserved noncoding sequences in grass species [Zhang et al., 2012b]. DHSs were also found to be hotspots for recruiting cytoplasmic organelle DNA in both plant and human [Wang and Timmis, 2013]; for example, chloroplast DNA preferentially inserts into rice DHSs, while mitochondrial DNA tends to insert more frequently into DHSs in human.

Genome-wide DHS datasets developed in rice and Arabidopsis allowed us to compare the distribution of DHSs in plants vs. humans. Among all DHSs analyzed, about $39 \%$ of DHSs are associated with introns in the human genome which is remarkably more than those in both rice (11\%) and Arabidopsis (5\%), respectively (fig. 2), indicating that considerably more regulatory elements target the introns in the human genome than in rice and Arabidopsis. This difference is most likely caused by the distinct difference in gene structure between human and plants. For example, the average intron size in human is about 6,155 bp which is significantly longer than the average 398- and 180-bp-long intron size in rice and Arabidopsis genes, respectively. In addition, total intron sequences cover about $76 \%$ of human genes which is also remarkably more than the roughly 38 and $30 \%$ of coverage found in rice and Arabidopsis genes, respectively. Due to a more compact genome, with a greater gene density and a lower percentage of intergenic sequences in Arabidopsis as compared to rice and humans, Arabidopsis has more DHSs present in putative promoter regions and less DHSs located in intergenic regions (fig. 2).

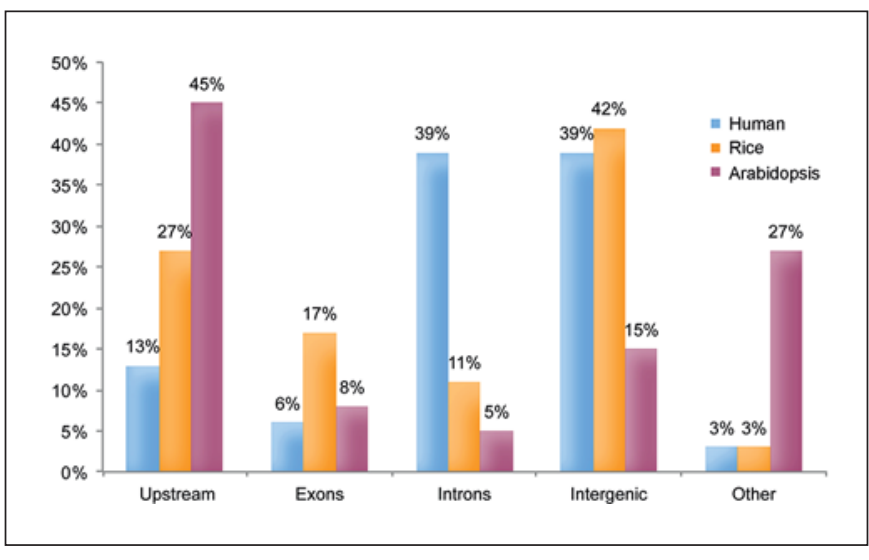

Fig. 2. Distribution of DHSs in rice, $A$. thaliana, and human. DHSs in upstream regions include all DHSs $2 \mathrm{~kb}$ upstream of human genes but $1 \mathrm{~kb}$ upstream of rice and $A$. thaliana genes. DHSs were collected from human primary $\mathrm{CD}^{+} \mathrm{T}$ cells [Boyle et al., 2008], rice seedlings [Zhang et al., 2012b], and 4 different tissues from $A$. thaliana (leaf and flower of wild type, leaf and flower from $d d m 1$ mutants, respectively) [Zhang et al., 2012b].

\section{Tissue-Specific DHSs}

It is well known that tissue-specific gene expression plays an essential role in tissue/cell identity which is most likely directed by tissue/cell-specific regulatory elements. Identification of tissue-specific CREs is not only a fundamental task in developmental biology but also paves the way to uncover the molecular mechanism of tissue differentiation and development. DNase-seq is an efficient and powerful approach for identifying dynamic changes in tissue/cell-specific DHSs in both human [Song et al., 2011] and plant genomes [Zhang et al., 2012a, b]. Among $\sim 870,000$ total DHSs across 7 different types of human cell lines, only $30-40 \%$ of DHSs overlap between any 2 cell types analyzed, indicating the majority of DHSs function in cell/tissue-type identity by regulating gene activities [Song et al., 2011]. Similarly, tissue-specific DHSs were also detected in both rice and Arabidopsis. Between 155,025 and 97,975 DHSs identified from rice callus and seedling tissues, respectively, there is only $49 \%(76,057)$ overlap between callus and seedling DHSs. Thus, approximately $51 \%$ of callus DHSs function in a tissue specific manner and are likely essential for initiation and maintenance of rice callus tissue [Zhang et al., 2012a]. In Arabidopsis, $24 \%(9,926$ of 41,000$)$ flower DHSs are flower specific, and $22 \%(8,520$ of 38,000$)$ leaf DHSs are unique in leaf tissue [Zhang et al., 2012b]. Further analysis showed that genes regulated by flower-specific DHSs mainly function in developmental regulation of flowers, embry- 
os, seeds, and fruits, supporting that tissue-specific DHSs function in the specification of corresponding tissues. For genomic locations, a high proportion of DHSs was detected in transcription start sites (TSSs) and intergenic regions of cell-type specific genes in human [Natarajan et al., 2012]. We also found DHSs enriched in TSS regions of either up-regulated or down-regulated genes in rice seedlings or calli [Zhang et al., 2012a]. Similarly, DHSs also significantly enriched around TSSs and $5^{\prime}$-UTRs of genes specific for Drosophila embryo development [Thomas et al., 2011].

\section{DNA Footprints Associated with DHSs in Plants}

Functions of CREs are determined by their interactions with regulatory proteins. The DNA sequences bound by regulatory proteins are shielded from nuclease cleavage as compared to immediately flanking regions, therefore resulting in the presence of DNA footprints [Galas and Schmitz, 1978]. Footprints of protein binding have been globally identified in both yeast and human using datasets derived from DNase-seq [Hesselberth et al., 2009; Boyle et al., 2011]. Similar analyses conducted in Arabidopsis demonstrated the power of DHS datasets in revealing protein-binding footprints [Zhang et al., 2012a]. The MADS-domain transcription factors APETALA1 (AP1) and SEPALLATA3 (SEP3) play key roles in regulating flower development in A. thaliana and are among the best characterized transcription factors in plants. Genome-wide AP1- and SEP3-binding sites were generated by ChIP-seq experiments [Kaufmann et al., 2009, 2010]. A total of 1,942 AP1- and 4,281 SEP3-binding sites were identified in flower tissue. We found that 1,843 (94.9\%) of the AP1-binding sites and 3,841 (89.7\%) of the SEP3-binding sites overlapped with DHSs identified in flower tissue. In addition, the ChIP-seq signal peaks of most AP1- and SEP3-binding sites overlapped with the DNase-seq signal peaks of the corresponding DHSs [Zhang et al., 2012a]. These results show that AP1- and SEP3-binding sites are well covered by DHSs, demonstrating the universal DNase I sensitivity associated with all CREs. In addition, the position of the $\mathrm{CC}[\mathrm{A} / \mathrm{T}]_{6} \mathrm{GG}$ motif specific for SEP3 binding was clearly less digested by DNase I compared to the flanking sequences which is most likely caused by the protection afforded by SEP3 binding [Zhang et al., 2012a]. Lastly, the same approach was extended to identify transcription factor binding footprints of a given genomic region [Zhang et al., 2012a, b]. For example, due to protection by MADS transcription factor binding, a clear footprint corresponding to a MADS box motif is only present in the promoter of the SUP gene from flower tissue but completely absent in the same locus from leaf tissue. These results showed that deep and high-quality DHS datasets can be used to confirm if a footprint is associated with the predicted or putative protein binding.

\section{Epigenetic Features of DHSs}

DHSs represent nucleosome depleted/dynamic regions in both human and plants, but well phased nucleosomes were clearly observed around all DHSs of the rice genome [Zhang et al., 2012b]. A distinct enrichment of H3K27me3, however, was observed within DHSs in the intergenic regions of the rice genome. Similarly, $\mathrm{H} 3 \mathrm{~K} 27 \mathrm{me} 3$ and $\mathrm{H} 3 \mathrm{~K} 9 \mathrm{me} 2 / 3$ modifications are enriched in distal DHSs in human [Boyle et al., 2008] which mostly are located within intergenic regions. The biological role of DHSs enriched with $\mathrm{H} 3 \mathrm{~K} 27 \mathrm{me} 3$ need to be further elucidated, although they possibly function in tissue specificity through regulating expression of tissue-specific genes in both plant and human.

At the underlying DNA level, local DNase I-sensitive regions with reduced DNA methylation have been reported in pea, barley, and corn chromatin [Klaas and Amasino, 1989]. At the genome wide level, all DHSs in rice show a lower level of DNA methylation than the flanking DNA sequences. Similar hypomethylation trends were also observed in seedling and callus specific DHSs within the genes and the 200-bp downstream regions of the genes. However, the methylation level of tissue-specific DHSs in promoters for rice is significantly elevated relative to the overall methylation level of all seedling DHSs within promoters, suggesting that differential DNA methylation in promoters of tissue-specific DHSs may play a key role in tissue-specific gene expression [Zhang et al., 2012a]. In the Populus trichocarpa genome, a negative correlation was observed between promoter and/or gene body methylation and tissue-specific gene expression levels [Vining et al., 2012]. Among 30,679 annotated genes in shoot apical meristematic (SAM) tissue, methylated DHSs were found to be strongly enriched within $26 \%$ promoter regions and $55 \%$ genebodies (exons) [Lafon-Placette et al., 2013] which is significantly higher than the overall methylation levels in the poplar genome (17\% for promoters and $15 \%$ for exons) [Vining et al., 2012]. These results indicate that differentially methylated DHSs within both promoters and exons are associated with tissue-specific gene expression in poplar. 


\section{Perspectives}

Plant genome research has entered the post-genome sequencing era. Sequencing of the entire genomes of plant species has become routine. Genes in a sequenced genome can now be readily identified and annotated by the powerful RNA-seq technique. However, the expression and regulation of genes in eukaryotes are controlled by an orchestrated binding of regulatory proteins to various types of CREs. Identification of CREs, especially those located outside of promoter regions, such as enhancers, has proven to be highly challenging. Thus, identification and characterization of CREs will be one of the future frontiers in plant genome research. DHS is a universal mark for all active CREs, thus, DHS provides a powerful tool for future CRE research.

Environmental abiotic stresses, such as drought, cold, heat, and high salinity, can induce various biochemical and physiological changes in plants which greatly affect plant growth and development. Understanding the mech- anisms for stress adaptation and tolerance is one of the most important and challenging goals in plant sciences and holds the key for future crop improvement. Growing evidence has indicated that epigenetic mechanisms are involved in the regulation of expression of stress-inducible genes [Chinnusamy and Zhu, 2009; Kim et al., 2010; Mirouze and Paszkowski, 2011]. Thus, abiotic stresses can alter chromatin structure which will ultimately impact the binding of regulatory proteins to CREs and affect the expression of the genes associated with CREs. Thus, we expect that DHS mapping will be a powerful tool to reveal CREs associated with stress response and to identify genes that can be manipulated for crop stress tolerance.

\section{Acknowledgments}

DHS research in our lab has been supported by grant (DBI0923640) from the National Science Foundation.

\section{References}

Almer A, Rudolph H, Hinnen A, Horz W: Removal of positioned nucleosomes from the yeast $\mathrm{PHO} 5$ promoter upon $\mathrm{PHO} 5$ induction releases additional upstream activating DNA elements. EMBO J 5:2689-2696 (1986).

-Auerbach RK, Euskirchen G, Rozowsky J, Lamarre-Vincent N, Moqtaderi Z, et al: Mapping accessible chromatin regions using Sono-Seq. Proc Natl Acad Sci USA 106:1492614931 (2009).

-Bell O, Schwaiger M, Oakeley EJ, Lienert F, Beisel C, et al: Accessibility of the Drosophila genome discriminates PcG repression, H4K16 acetylation and replication timing. Nat Struct Mol Biol 17:894-900 (2010).

-Bell O, Tiwari VK, Thoma NH, Schubeler D: Determinants and dynamics of genome accessibility. Nat Rev Genet 12:554-564 (2011).

-Bender MA, Bulger M, Close J, Groudine M: Betaglobin gene switching and DNase I sensitivity of the endogenous beta-globin locus in mice do not require the locus control region. $\mathrm{Mol}$ Cell 5:387-393 (2000)

Bernstein BE, Birney E, Dunham I, Green ED, Gunter C, et al: An integrated encyclopedia of DNA elements in the human genome. Nature 489:57-74 (2012).

Birney E, Stamatoyannopoulos JA, Dutta A, Guigo $\mathrm{R}$, Gingeras $\mathrm{TR}$, et al: Identification and analysis of functional elements in $1 \%$ of the human genome by the ENCODE pilot project. Nature 447:799-816 (2007).
Bischof JM, Ott CJ, Leir SH, Gosalia N, Song L, et al: A genome-wide analysis of open chromatin in human tracheal epithelial cells reveals novel candidate regulatory elements for lung function. Thorax 67:385-391 (2012).

Bloom KS, Carbon J: Yeast centromere DNA is in a unique and highly ordered structure in chromosomes and small circular minichromosomes. Cell 29:305-317 (1982).

Borchsenius S, Bonven B, Leer JC, Westergaard $\mathrm{O}$ : Nuclease-sensitive regions on the extrachromosomal r-chromatin from Tetrahymena pyriformis. Eur J Biochem 117:245-250 (1981).

Boyle AP, Davis S, Shulha HP, Meltzer P, Margulies EH, et al: High-resolution mapping and characterization of open chromatin across the genome. Cell 132:311-322 (2008).

Boyle AP, Song L, Lee BK, London D, Keefe D, et al: High-resolution genome-wide in vivo footprinting of diverse transcription factors in human cells. Genome Res 21:456-464 (2011).

Budarf ML, Blackburn EH: Chromatin structure of the telomeric region and 3 '-nontranscribed spacer of Tetrahymena ribosomal RNA genes. J Biol Chem 261:363-369 (1986).

Buenrostro JD, Giresi PG, Zaba LC, Chang HY, Greenleaf WJ: Transposition of native chromatin for fast and sensitive epigenomic profiling of open chromatin, DNA-binding proteins and nucleosome position. Nat Methods 10:1213-1218 (2013).
Bulger M, Schubeler D, Bender MA, Hamilton J, Farrell CM, et al: A complex chromatin landscape revealed by patterns of nuclease sensitivity and histone modification within the mouse beta-globin locus. Mol Cell Biol 23: 5234-5244 (2003).

Cartwright IL, Elgin SC: Analysis of chromatin structure and DNA sequence organization: use of the 1,10-phenanthroline-cuprous complex. Nucleic Acids Res 10:5835-5852 (1982).

Cartwright IL, Hertzberg RP, Dervan PB, Elgin SC: Cleavage of chromatin with methidiumpropyl-EDTA.iron(ii). Proc Natl Acad Sci USA 80:3213-3217 (1983).

Chinnusamy V, Zhu JK: Epigenetic regulation of stress responses in plants. Curr Opin Plant Biol 12:133-139 (2009).

Cockerill PN: Structure and function of active chromatin and DNase I hypersensitive sites. FEBS J 278:2182-2210 (2011).

Conconi A, Ryan CA: DNase I and micrococcal nuclease analysis of the tomato proteinase inhibitor I gene in chromatin. J Biol Chem 268: 430-435 (1993).

Crawford GE, Holt IE, Mullikin JC, Tai D, Blakesley $\mathrm{R}$, et al: Identifying gene regulatory elements by genome-wide recovery of DNase hypersensitive sites. Proc Natl Acad Sci USA 101:992-997 (2004).

Crawford GE, Davis S, Scacheri PC, Renaud G, Halawi MJ, et al: DNase-chip: a high-resolution method to identify DNase I hypersensitive sites using tiled microarrays. Nat Methods 3:503-509 (2006a). 
-Crawford GE, Holt IE, Whittle J, Webb BD, Tai $\mathrm{D}$, et al: Genome-wide mapping of DNase hypersensitive sites using massively parallel signature sequencing (MPSS). Genome Res 16: 123-131 (2006b).

Dekker J, Rippe K, Dekker M, Kleckner N: Capturing chromosome conformation. Science 295:1306-1311 (2002).

-Dimitrova AD, Ananiev ED, Gecheff KI: DNase I hypersensitive sites within the intergenic spacer of ribosomal RNA genes in reconstructed barley karyotypes. Biotechnol Biotechnol Equip 23:1039-1043 (2009).

- Dorschner MO, Hawrylycz M, Humbert R, Wallace JC, Shafer A, et al: High-throughput localization of functional elements by quantitative chromatin profiling. Nat Methods 1:219225 (2004).

Dostie J, Dekker J: Mapping networks of physical interactions between genomic elements using 5C technology. Nat Protoc 2:988-1002 (2007).

Eissenberg JC, Cartwright IL, Thomas GH, Elgin SC: Selected topics in chromatin structure. Annu Rev Genet 19:485-536 (1985).

Elgin SC: DNase I-hypersensitive sites of chromatin. Cell 27:413-415 (1981).

Fagrelius TJ, Livingston DM: Location of DNase I sensitive cleavage sites in the yeast 2 micron plasmid DNA chromosome. J Mol Biol 173: $1-13$ (1984).

Feng J, Villeponteau B: High-resolution analysis of c-fos chromatin accessibility using a novel DNase I-PCR assay. Biochim Biophys Acta 1130:253-258 (1992)

-Ferl RJ, Nick HS: In vivo detection of regulatory factor binding sites in the 5 flanking region of maize Adh1. J Biol Chem 262:7947-7950 (1987).

Follows GA, Janes ME, Vallier L, Green AR, Gottgens B: Real-time PCR mapping of DNaseIhypersensitive sites using a novel ligationmediated amplification technique. Nucleic Acids Res 35:e56 (2007).

Fritton HP, Sippel AE, Igo-Kemenes T: Nucleasehypersensitive sites in the chromatin domain of the chicken lysozyme gene. Nucleic Acids Res 11:3467-3485 (1983).

Fullwood MJ, Liu MH, Pan YF, Liu J, Xu H, et al: An oestrogen-receptor-alpha-bound human chromatin interactome. Nature 462:58-64 (2009).

Galas DJ, Schmitz A: DNase footprinting: a simple method for the detection of protein-DNA binding specificity. Nucleic Acids Res 5: 3157-3170 (1978).

- Gargiulo G, Razvi F, Ruberti I, Mohr I, Worcel A: Chromatin-specific hypersensitive sites are assembled on a Xenopus histone gene injected into Xenopus oocytes. J Mol Biol 181:333-349 (1985).

- Gerstein MB, Lu ZJ, Van Nostrand EL, Cheng C, Arshinoff BI, et al: Integrative analysis of the Caenorhabditis elegans genome by the modENCODE project. Science 330:1775-1787 (2010).
Giresi PG, Kim J, McDaniell RM, Iyer VR, Lieb JD: FAIRE (formaldehyde-assisted isolation of regulatory elements) isolates active regulatory elements from human chromatin. Genome Res 17:877-885 (2007).

Gorz A, Schafer W, Hirasawa E, Kahl G: Constitutive and light-induced DNaseI hypersensitive sites in the $r b c S$ genes of pea (Pisum sativum). Plant Mol Biol 11:561-573 (1988).

Gross DS, Garrard WT: Nuclease hypersensitive sites in chromatin. Annu Rev Biochem 57: 159-197 (1988).

Grosveld F, van Assendelft GB, Greaves DR, Kol lias G: Position-independent, high-level expression of the human beta-globin gene in transgenic mice. Cell 51:975-985 (1987).

-Groudine M, Kohwi-Shigematsu T, Gelinas R, Stamatoyannopoulos G, Papayannopoulou T: Human fetal to adult hemoglobin switching: changes in chromatin structure of the beta-globin gene locus. Proc Natl Acad Sci USA 80:7551-7555 (1983).

Heintzman ND, Stuart RK, Hon G, Fu Y, Ching $\mathrm{CW}$, et al: Distinct and predictive chromatin signatures of transcriptional promoters and enhancers in the human genome. Nat Genet 39:311-318 (2007).

Heintzman ND, Hon GC, Hawkins RD, Kheradpour P, Stark A, et al: Histone modifications at human enhancers reflect global cell-typespecific gene expression. Nature 459:108-112 (2009).

Hesselberth JR, Chen X, Zhang Z, Sabo PJ, Sandstrom R, et al: Global mapping of proteinDNA interactions in vivo by digital genomic footprinting. Nat Methods 6:283-289 (2009).

Hogan GJ, Lee CK, Lieb JD: Cell cycle-specified fluctuation of nucleosome occupancy at gene promoters. PLoS Genet 2:e158 (2006).

John S, Sabo PJ, Canfield TK, Lee K, Vong S, et al: Genome-scale mapping of DNase I hypersensitivity. Curr Protoc Mol Biol Chapter 27: Unit21 27 (2013).

-Johnson DS, Mortazavi A, Myers RM, Wold B: Genome-wide mapping of in vivo proteinDNA interactions. Science 316:1497-1502 (2007).

Kaufmann K, Muino JM, Jauregui R, Airoldi CA, Smaczniak C, et al: Target genes of the MADS transcription factor SEPALLATA3: integration of developmental and hormonal pathways in the Arabidopsis flower. PLoS Biol 7: 854-875 (2009).

Kaufmann K, Wellmer F, Muino JM, Ferrier T, Wuest SE, et al: Orchestration of floral initiation by APETALA1. Science 328:85-89 (2010).

Kaye JS, Bellard M, Dretzen G, Bellard F, Chambon P: A close association between sites of DNase I hypersensitivity and sites of enhanced cleavage by micrococcal nuclease in the $5^{\prime}$-flanking region of the actively transcribed ovalbumin gene. EMBO J 3:11371144 (1984).
Keene MA, Corces V, Lowenhaupt K, Elgin SC: DNase I hypersensitive sites in Drosophila chromatin occur at the $5^{\prime}$ ends of regions of transcription. Proc Natl Acad Sci USA 78: 143-146 (1981).

Kim JM, To TK, Nishioka T, Seki M: Chromatin regulation functions in plant abiotic stress responses. Plant Cell Environ 33:604-611 (2010)

Klaas M, Amasino RM: DNA methylation is reduced in DNasel-sensitive regions of plant chromatin. Plant Physiol 91:451-454 (1989).

Kodama Y, Nagaya S, Shinmyo A, Kato K: Distinct DNase I hypersensitive sites are absent from promoters of transcriptionally incompetent genes in Arabidopsis. Plant Biotechnology 24:383-392 (2007a).

Kodama Y, Nagaya S, Shinmyo A, Kato K: Mapping and characterization of DNase I hypersensitive sites in Arabidopsis chromatin. Plant Cell Physiol 48:459-470 (2007b).

Kolovos P, Knoch TA, Grosveld FG, Cook PR, Papantonis A: Enhancers and silencers: an integrated and simple model for their function. Epigenetics Chromatin 5:1 (2012)

Krebs JE, Peterson CL: Understanding 'active' chromatin: a historical perspective of chromatin remodeling. Crit Rev Eukaryot Gene Expr 10:1-12 (2000)

Lafon-Placette C, Faivre-Rampant P, Delaunay A, Street N, Brignolas F, et al: Methylome of DNase I sensitive chromatin in Populus trichocarpa shoot apical meristematic cells: a simplified approach revealing characteristics of gene-body DNA methylation in open chromatin state. New Phytol 197:416-430 (2013).

Lieberman-Aiden E, van Berkum NL, Williams L, Imakaev M, Ragoczy T, et al: Comprehensive mapping of long-range interactions reveals folding principles of the human genome. Science 326:289-293 (2009).

Lodha M, Schroda M: Analysis of chromatin structure in the control regions of the Chlamydomonas HSP70A and RBCS2 genes. Plant Mol Biol 59:501-513 (2005)

Loer DS, Spiker S: Chromatin structure of heatshock-inducible genes and abscisic acid-inducible genes in wheat. Physiologia Plantarum 86:77-84 (1992).

Lohr D: Organization of the GAL1-GAL10 intergenic control region chromatin. Nucleic Acids Res 12:8457-8474 (1984).

Louwers M, Bader R, Haring M, van Driel R, de Laat $\mathrm{W}$, et al: Tissue- and expression levelspecific chromatin looping at maize B1 epialleles. Plant Cell 21:832-842 (2009).

-Martins RP, Platts AE, Krawetz SA: Tracking chromatin states using controlled DNase I treatment and real-time PCR. Cell Mol Biol Lett 12:545-555 (2007).

Mather EL, Perry RP: Methylation status and DNase I sensitivity of immunoglobulin genes: changes associated with rearrangement. Proc Natl Acad Sci USA 80:4689-4693 (1983). 
McArthur M, Gerum S, Stamatoyannopoulos G: Quantification of DNaseI-sensitivity by realtime PCR: quantitative analysis of DNaseIhypersensitivity of the mouse beta-globin LCR. J Mol Biol 313:27-34 (2001).

-McGhee JD, Wood WI, Dolan M, Engel JD, Felsenfeld G: A 200 base pair region at the $5^{\prime}$ end of the chicken adult beta-globin gene is accessible to nuclease digestion. Cell 27:45-55 (1981).

-McGinnis W, Shermoen AW, Beckendorf SK: A transposable element inserted just $5^{\prime}$ to a Drosophila glue protein gene alters gene expression and chromatin structure. Cell 34:75-84 (1983).

-Mirouze M, Paszkowski J: Epigenetic contribution to stress adaptation in plants. Curr Opin Plant Biol 14:267-274 (2011).

- Muse GW, Gilchrist DA, Nechaev S, Shah R, Parker JS, et al: RNA polymerase is poised for activation across the genome. Nat Genet 39: 1507-1511 (2007).

-Natarajan A, Yardimci GG, Sheffield NC, Crawford GE, Ohler U: Predicting cell-type-specific gene expression from regions of open chromatin. Genome Res 22:1711-1722 (2012).

-Nelson JA, Groudine M: Transcriptional regulation of the human cytomegalovirus major immediate-early gene is associated with induction of DNase I-hypersensitive sites. Mol Cell Biol 6:452-461 (1986)

Neph S, Vierstra J, Stergachis AB, Reynolds AP, Haugen E, et al: An expansive human regulatory lexicon encoded in transcription factor footprints. Nature 489:83-90 (2012).

Ness PJ, Parish RW, Koller T: Mapping of endogenous nuclease-sensitive regions and of putative topoisomerase sites of action along the chromatin of Dictyostelium ribosomal RNA genes. J Mol Biol 188:287-300 (1986).

-Ong CT, Corces VG: Enhancer function: new insights into the regulation of tissue-specific gene expression. Nat Rev Genet 12:283-293 (2011).

- Parelho V, Hadjur S, Spivakov M, Leleu M, Sauer $\mathrm{S}$, et al: Cohesins functionally associate with CTCF on mammalian chromosome arms. Cell 132:422-433 (2008).

-Pfeifer GP, Riggs AD: Chromatin differences between active and inactive $\mathrm{X}$ chromosomes revealed by genomic footprinting of permeabilized cells using DNase I and ligation-mediated PCR. Genes Dev 5:1102-1113 (1991).

- Roy S, Ernst J, Kharchenko PV, Kheradpour P, Negre N, et al: Identification of functional elements and regulatory circuits by Drosophila modENCODE. Science 330:1787-1797 (2010).

-Sabo PJ, Humbert R, Hawrylycz M, Wallace JC, Dorschner MO, et al: Genome-wide identification of DNaseI hypersensitive sites using active chromatin sequence libraries. Proc Natl Acad Sci USA 101:4537-4542 (2004).

-Sabo PJ, Kuehn MS, Thurman R, Johnson BE, Johnson EM, et al: Genome-scale mapping of DNase I sensitivity in vivo using tiling DNA microarrays. Nat Methods 3:511-518 (2006).
Sajan SA, Hawkins RD: Methods for identifying higher-order chromatin structure. Annu Rev Genomics Hum Genet 13:59-82 (2012).

- Saxena P, Fowke L, J K: An efficient procedure for isolation of nuclei from plant protoplasts. Protoplasma 128:184-189 (1985).

Schaub MA, Boyle AP, Kundaje A, Batzoglou S, Snyder M: Linking disease associations with regulatory information in the human genome. Genome Res 22:1748-1759 (2012).

Schones DE, Cui K, Cuddapah S, Roh TY, Barski $A$, et al: Dynamic regulation of nucleosome positioning in the human genome. Cell 132: 887-898 (2008).

Scott WA, Wigmore DJ: Sites in simian virus 40 chromatin which are preferentially cleaved by endonucleases. Cell 15:1511-1518 (1978).

-Scott WA, Walter CF, Cryer BL: Barriers to nuclease Bal31 digestion across specific sites in simian virus 40 chromatin. Mol Cell Biol 4:604610 (1984).

- Senear AW, Palmiter RD: Expression of the mouse metallothionein-I gene alters the nuclease hypersensitivity of its $5^{\prime}$ regulatory region. Cold Spring Harb Symp Quant Biol 47 Pt 1:539-547 (1983).

- Shore D, Stillman DJ, Brand AH, Nasmyth KA: Identification of silencer binding proteins from yeast: possible roles in SIR control and DNA replication. EMBO J 6:461-467 (1987).

-Shu H, Wildhaber T, Siretskiy A, Gruissem W, Hennig L: Distinct modes of DNA accessibility in plant chromatin. Nat Commun 3:1281 (2012).

-Shu H, Gruissem W, Hennig L: Measuring Arabidopsis chromatin accessibility using DNase Ipolymerase chain reaction and DNase I-chip assays. Plant Physiol 162:1794-1801 (2013).

-Shu W, Chen H, Bo X, Wang S: Genome-wide analysis of the relationships between DNaseI HS, histone modifications and gene expression reveals distinct modes of chromatin domains. Nucleic Acids Res 39:7428-7443 (2011).

Sikorskaite S, Rajamaki ML, Baniulis D, Stanys V, Valkonen JP: Protocol: optimised methodology for isolation of nuclei from leaves of species in the Solanaceae and Rosaceae families. Plant Methods 9:31 (2013).

Song L, Crawford GE: DNase-Seq: a high-resolution technique for mapping active gene regulatory elements across the genome from mammalian cells. Cold Spring Harb Protoc 2010:pdb prot5384 (2010).

Song L, Zhang Z, Grasfeder LL, Boyle AP, Giresi PG, et al: Open chromatin defined by DNaseI and FAIRE identifies regulatory elements that shape cell-type identity. Genome Res 21: 1757-1767 (2011).

-Stalder J, Larsen A, Engel JD, Dolan M, Groudine $\mathrm{M}$, et al: Tissue-specific DNA cleavages in the globin chromatin domain introduced by DNase I. Cell 20:451-460 (1980).

-Stamatoyannopoulos JA, Snyder M, Hardison R, Ren B, Gingeras T, et al: An encyclopedia of mouse DNA elements (mouse ENCODE). Genome Biol 13:418 (2012).
Stitzel ML, Sethupathy P, Pearson DS, Chines PS, Song L, et al: Global epigenomic analysis of primary human pancreatic islets provides insights into type 2 diabetes susceptibility loci. Cell Metab 12:443-455 (2010).

-Storb U, Arp B, Wilson R: The switch region associated with immunoglobulin $\mathrm{C}$ mu genes is DNase I hypersensitive in $\mathrm{T}$ lymphocytes. $\mathrm{Na}$ ture 294:90-92 (1981).

- Thomas S, Li XY, Sabo PJ, Sandstrom R, Thurman RE, et al: Dynamic reprogramming of chromatin accessibility during Drosophila embryo development. Genome Biol 12:R43 (2011).

Thompson WF, Flavell RB: DNase I sensitivity of ribosomal RNA genes in chromatin and nucleolar dominance in wheat. J Mol Biol 204: 535-548 (1988).

- Thomsen B, Mollerup S, Bonven BJ, Frank R, Blocker $\mathrm{H}$, et al: Sequence specificity of DNA topoisomerase I in the presence and absence of camptothecin. EMBO J 6:1817-1823 (1987).

Thurman RE, Rynes E, Humbert R, Vierstra J, Maurano MT, et al: The accessible chromatin landscape of the human genome. Nature 489: 75-82 (2012).

Tiwari VK, Cope L, McGarvey KM, Ohm JE, Baylin SB: A novel 6C assay uncovers Polycombmediated higher order chromatin conformations. Genome Res 18:1171-1179 (2008).

Todd MJ, Harrison JW: An evaluation of the immediate and early sealing properties of Cavit. J Endod 5:362-367 (1979).

-Udvardy A, Schedl P, Sander M, Hsieh TS: Topoisomerase II cleavage in chromatin. J Mol Biol 191:231-246 (1986).

- Valenzuela L, Kamakaka RT: Chromatin insulators. Annu Rev Genet 40:107-138 (2006).

- Varshavsky AJ, Sundin OH, Bohn MJ: SV40 viral minichromosome: preferential exposure of the origin of replication as probed by restriction endonucleases. Nucleic Acids Res 5: 3469-3477 (1978)

Varshavsky AJ, Sundin O, Bohn M: A stretch of 'late' SV40 viral DNA about 400 bp long which includes the origin of replication is specifically exposed in SV40 minichromosomes. Cell 16:453-466 (1979).

-Vega-Palas MA, Ferl RJ: The Arabidopsis Adh gene exhibits diverse nucleosome arrangements within a small DNase I-sensitive domain. Plant Cell 7:1923-1932 (1995).

Vernot B, Stergachis AB, Maurano MT, Vierstra J, Neph S, et al: Personal and population genomics of human regulatory variation. Genome Res 22:1689-1697 (2012).

Vining KJ, Pomraning KR, Wilhelm LJ, Priest HD, Pellegrini M, et al: Dynamic DNA cytosine methylation in the Populus trichocarpa genome: tissue-level variation and relationship to gene expression. BMC Genomics 13: 27 (2012).

Wallace JA, Felsenfeld G: We gather together: insulators and genome organization. Curr Opin Genet Dev 17:400-407 (2007). 
Wang D, Timmis JN: Cytoplasmic organelle DNA preferentially inserts into open chromatin. Genome Biol Evol 5:1060-1064 (2013).

Wang YM, Zhou P, Wang LY, Li ZH, Zhang YN et al: Correlation between DNase I hypersensitive site distribution and gene expression in HeLa S3 cells. PLoS One 7:e42414 (2012).

-Weil MR, Widlak P, Minna JD, Garner HR: Global survey of chromatin accessibility using DNA microarrays. Genome Res 14:13741381 (2004).

Weisbrod S, Weintraub H: Isolation of a subclass of nuclear proteins responsible for conferring a DNase I-sensitive structure on globin chromatin. Proc Natl Acad Sci USA 76:630-634 (1979).

-Winter DR, Song L, Mukherjee S, Furey TS, Crawford GE: DNase-Seq predicts regions of rotational nucleosome stability across diverse human cell types. Genome Res 23:1118-1129 (2013).
Wu C: The $5^{\prime}$ ends of Drosophila heat shock genes in chromatin are hypersensitive to DNase I. Nature 286:854-860 (1980).

Wu C, Bingham PM, Livak KJ, Holmgren R, Elgin SC: The chromatin structure of specific genes: I. Evidence for higher order domains of defined DNA sequence. Cell 16:797-806 (1979).

Yagi M, Gelinas R, Elder JT, Peretz M, Papayannopoulou $\mathrm{T}$, et al: Chromatin structure and developmental expression of the human alpha-globin cluster. Mol Cell Biol 6:1108-1116 (1986).

Yilmaz A, Grotewold E: Components and mechanisms of regulation of gene expression. Methods Mol Biol 674:23-32 (2010).

-You JS, Kelly TK, De Carvalho DD, Taberlay PC, Liang G, et al: OCT4 establishes and maintains nucleosome-depleted regions that provide additional layers of epigenetic regulation of its target genes. Proc Natl Acad Sci USA 108:14497-14502 (2011).

Zeitlinger J, Stark A, Kellis M, Hong JW, Nechaev $\mathrm{S}$, et al: RNA polymerase stalling at developmental control genes in the Drosophila melanogaster embryo. Nat Genet 39:1512-1516 (2007).
Zentner GE, Tesar PJ, Scacheri PC: Epigenetic signatures distinguish multiple classes of enhancers with distinct cellular functions. Genome Res 21:1273-1283 (2011).

Zhang W, Wu Y, Schnable JC, Zeng Z, Freeling $\mathrm{M}$, et al: High-resolution mapping of open chromatin in the rice genome. Genome Res 22:151-162 (2012a).

Zhang W, Zhang T, Wu Y, Jiang J: Genome-wide identification of regulatory DNA elements and protein-binding footprints using signatures of open chromatin in Arabidopsis. Plant Cell 24:2719-2731 (2012b).

Zhao Z, Tavoosidana G, Sjolinder M, Gondor A, Mariano P, et al: Circular chromosome conformation capture (4C) uncovers extensive networks of epigenetically regulated intraand interchromosomal interactions. Nat Genet 38:1341-1347 (2006). 